\title{
Starting the new review series, rationale and practical method for lifestyle modification
}

\author{
Toshihiko Ishimitsu Editor-in-chief ${ }^{1}$
}

Published online: 20 September 2019

(c) The Japanese Society of Hypertension 2019

High blood pressure facilitates the progression of arteriosclerosis that increases the incidence of cardiovascular diseases, such as stroke and coronary heart disease. Hypertension is also a major risk factor for the development of cardiovascular organ damages, such as heart failure and renal dysfunction. Considering that the population of elderly people at high risks for cardiovascular events is globally growing, adequate control of blood pressure is of primary importance in order to prevent cardiovascular disorders and elongate the healthy life prognosis.

Regarding the relationship between the blood pressure level and the cardiovascular risk, there is not an apparent threshold level from which higher blood pressure is associated with the increase in cardiovascular diseases. Metaanalysis of prospective observational studies has indicated that the risk of cardiovascular diseases, such as stroke and myocardial infarction, increase with increasing blood pressure level and this relationship can be extended even in the normal blood pressure range down to $115 / 75 \mathrm{mmHg}$ [1]. In addition, the Systolic Blood Pressure Intervention Trial showed that the intensive treatment in high-risk hypertensive patients with target SBP $<120 \mathrm{mmHg}$ reduced the rates of cardiovascular events and death as compared with the standard treatment group targeted $<140 \mathrm{mmHg}$ [2].

With these backgrounds, the American guideline for the management of high blood pressure (ACC/AHA2017) has lowered the definition level of hypertension to 130/ $80 \mathrm{mmHg}$ or higher [3]. However, the evidence by randomized controlled trials is not necessarily sufficient as to the benefit of targeting this blood pressure level in antihypertensive drug therapy of low to moderate risk hypertensive patients [4]. Therefore, the following European

Toshihiko Ishimitsu

isimitu@dokkyomed.ac.jp

1 Department of Cardiology and Nephrology, Dokkyo Medical University, Mibu, Japan
(ESC/ESH2018) and Japanese (JSH2019) guidelines for the management of hypertension $[5,6]$ have inherited the diagnostic criteria of hypertension as $140 / 90 \mathrm{mmHg}$ or higher.

In these three guidelines, initiation or reinforcement of lifestyle modification is recommended to subjects with 130-139/80-89 mmHg blood level because it costs much less and causes less adverse effects than drug therapy. Even in patients on antihypertensive medication, the reinforcement of lifestyle modification is expected to augment the hypotensive effects of drugs and to reduce the number and doses of antihypertensive drugs. Accordingly, the importance of lifestyle modification is emphasized at this time in the management of hypertensive patients.

Table 1 lists the items of lifestyle modification indicated by the Japanese JSH2019 guideline [6]. In the practical treatment of hypertensive patients, comprehensive instruction of multiple lifestyle modifications is more effective than each item alone. Moreover, these approaches are effective not only in lowering blood pressure but also in

Table 1 Points of lifestyle modifications in The Japanese Society of Hypertension for Guidelines for the Management of Hypertension (JSH2019) [6]

1. Salt reduction to $<6 \mathrm{~g}$ per day

2. Increased intake of vegetables/fruit ${ }^{\mathrm{a}}$; reduced intake of saturated fatty acids and cholesterol; increased intake of polyunsaturated fatty acids and low fat dairy products

3. Maintaining proper body weight: BMI ([body weight $\left.(\mathrm{kg})] \div[\text { height }(\mathrm{m})]^{2}\right):<25$

4. Exercise therapy: Mild aerobic exercise (dynamic/static muscle load exercise) for at least $30 \mathrm{~min} /$ day or $180 \mathrm{~min} /$ week

5. Reduction of alcohol intake: $\leq 20-30 \mathrm{~mL}$ ethanol per day in men and $\leq 10-20 \mathrm{~mL}$ ethanol per day in women

6. Smoking cessation

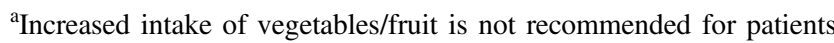
with renal dysfunction requiring restriction of potassium intake. Fruit intake should not exceed about $80 \mathrm{kcal} /$ day in patients who need to restrict their energy intake, such as obese and diabetic patients 
improving other lifestyle-related disorders, such as diabetes mellitus, dyslipidemia, and obesity. In the series of review articles starting from this issue of Hypertension Research, the updated strategies, newest insights, and future perspectives of lifestyle modifications will be discussed as to salt reduction, correction of obesity, exercise, smoke cessation, and moderation of alcohol intake, etc.

\section{Compliance with ethical standards}

Conflict of interest The author declares that he has no conflict of interest.

Publisher's note Springer Nature remains neutral with regard to jurisdictional claims in published maps and institutional affiliations.

\section{References}

1. Lewington S, Clarke R, Qizilbash N, Peto R, Collins R. Agespecific relevance of usual blood pressure to vascular mortality: a meta-analysis of individual data for one million adults in 61 prospective studies. Lancet. 2002;360:1903-13.

2. SPRINT Research Group. A randomized trial of intensive versus standard blood-pressure control. N Engl J Med. 2015;373:2103-16.

3. Whelton PK, Carey RM, Aronow WS, Casey DE Jr, Collins KJ, Dennison Himmelfarb C, et al. 2017 ACC/AHA/AAPA/ABC/ ACPM/AGS/APhA/ASH/ASPC/NMA/PCNA Guideline for the prevention, detection, evaluation, and management of high blood pressure in adults: a report of the American College of Cardiology/ American Heart Association Task Force on Clinical Practice Guidelines. Hypertension. 2018;71:e13-e115.

4. Helgeland A. Treatment of mild hypertension: a five year controlled drug trial. The Oslo study. Am J Med. 1980;69:725-32.

5. Williams B, Mancia G, Spiering W, Agabiti Rosei E, Azizi M, et al. 2018 ESC/ESH guidelines for the management of arterial hypertension: the Task Force for the management of arterial hypertension of the European Society of Cardiology and the European Society of Hypertension: the Task Force for the management of arterial hypertension of the European Society of Cardiology and the European Society of Hypertension. J Hypertens. 2018;36:1953-2041.

6. Umemura S, Arima H, Arima S, Asayama K, Dohi Y, Hirooka Y, et al. The Japanese Society of Hypertension Guidelines for the Management of Hypertension (JSH 2019). Hypertens Res. 2019;42:1235-481. 